\title{
Empowering the Apprentice Academic: Teaching Writing at Postgraduate Level
}

This article describes the development by applied linguists of two series of workshops and individual tutorials at a New Zealand university. This bipartite course was designed for Business, and Art and Design students engaged in post-graduate programs that require extended writing. Doctoral business students write a thesis of approximately 50,000-75,000 words, Masters students may write a thesis or a dissertation of approximately 20,000 words, and Art and Design Masters students write an exegesis to accompany their final examination exhibition, which is also approximately 20,000 words. The discussion begins with a review of the context for such support and of the key issue of taking a discipline-specific approach. It then details the parameters and development of the workshops. Next, it focuses on the aims and provision of the individual tutorials, as it is at this stage that students have the opportunity to work and explain their concepts in an egalitarian way, and not be caught up in the clearly defined master-apprentice status inherent in the supervisory role. Finally, it reflects on how these experiences are being translated into online discipline-specific writing support.

By the time students arrive at the stage of concentrating on writing their dissertation, thesis, or exegesis they are likely to have completed a research methods course, to have been exposed to a range of academic texts in their field, to have written assignments in taught courses as well as their research proposal, and to have had discussions with their supervisor about approaches to research and writing. However, research reveals that students do not always possess the knowledge of discourse expectations necessary for success in writing the thesis (Bitchener and Basturkmen, 2006; Cadman, 1997; Cooley and Lewkowicz, 1995, 1997; Dong, 1998; James, 1984; Jenkins, Jordan and Weiland, 1993; Parry, 1998; Pearson Casanave and Hubbard, 1992). Possible reasons include the fact that the focus of research methods courses is largely on approaches to research.

Supervisors we interviewed point out that students often have difficulties in clearly explaining and sequencing propositions, and in creating effective transitions between propositions and between topics or themes. They may have difficulties with the 
development of ideas and the organization of argument (Cadman, 1997; Cooley and Lewkowicz, 1995, 1997; Dong, 1998; Pearson Casanave and Hubbard, 1992; Thompson, 1999). As a result of their cultural, linguistic, and educational traditions, English as an additional language (EAL) students are likely to have, to varying degrees, differing perceptions of conventions of argument, and differing priorities in terms of what is valued in writing by English-speaking universities (Canagarajah, 1996; Nagata, 1999; Pearson Casanave and Hubbard, 1992; Cadman, 1997; Allison, Cooley, Lewkowicz and Nunan, 1998). Both EAL and native English users may have a lack of understanding of the discourse requirements involved in writing a thesis. (Bitchener and Basturkmen, 2006; Cooley and Lewkowicz, 1995, 1997; Dong, 1998; Parry, 1998).

Hyland (2002:391) argues strongly in favor of discipline-specific language teaching that recognizes the disciplinary requirements and subject expertise of learners. He clarifies that disciplinary preferences and practices are reflected in features of argument, control of "rhetorical personality," and the ways in which writers engage readers. Discipline-specific workshops that explain and exemplify disciplinary habits and specific requirements have can create a knowledge framework for subsequent tutorials. . Individual writing tutorials or consultations are necessarily embedded in the context of disciplinary goals, practices, and expectations. They allow for a focus on the writing of individual students and their production of discipline-specific texts, and, in particular, for clarification of meaning and for a dialogue that operates within each student's zone of proximal development of meaning (Vygotsky, 1978; Woodward-Kron, 2007). We describe here the development of two series of discipline-specific workshops that are followed by individual tutorials or consultations.

\section{Development of the Workshops to Support Discipline-Specific Thesis Writing} Results based on a two-year longitudinal study of EAL students and their supervisors (Strauss, Walton, and Madsen, 2003; Strauss and Walton, 2005) indicate that there are several areas in the preparation for thesis writing for which students within the same discipline area require some general instruction, while students' individual academic literacy issues, particularly relating to the expression of meaning, also need to be addressed. This bi-partite approach to empowering students in their advanced 
academic writing is further supported by the literature (Green, 2005; Lea, 2004; Lillis, 2003). In response to a request in 2005 for academic literacy assistance for EAL postgraduate students by the Business Faculty at our university, the authors' response was to propose an initial workshop of three hours, followed by one-on-one tutorials. In response to student feedback from the first workshop, the assistance was extended to two two-hour workshops. As we initially planned the workshop, we arranged a meeting in the Business Faculty with colleagues to clarify their explicit expectations for the dissertation. These were, first, the effective planning of the narrative so that the argument was logically structured, together with clarity of expression and consistency of approach with regard to APA-style referencing and the use of personal and impersonal voice. Further, the avoidance of unsubstantiated claims, and explicit connections between citation and text were expected. Finally, our colleagues emphasized the need for the use of metadiscourse markers, for example "In the previous chapter the literature was reviewed. In this chapter the research methodology will be introduced, followed by ...”

The applied linguists (ALs) planning the workshops needed to study the generic discipline requirements, realizing that this involved several subdisciplines, including finance, marketing, and taxation law. Approaches to constructing an argument, reviewing the literature, and use of tentative language (i.e. language which delineates the writer's position as an apprentice within the academy, using softening modifiers or hedges rather than strong statements), proved to be quite similar across the subdisciplines. The ALs read appropriate journal articles and studied examples of theses. Use of passive and active voice with verb forms and the type of hedging use across subdisciplines were two of the major areas of variance found, with the area of taxation law showing the most directness. When teaching the workshops, the ALs give explicit examples of hedging language, verb use, and those discourse markers which clarify the construction of the argument, derived from actual examples from relevant texts or published theses. These examples are also given as a handout for the students to use later as a reference or model when writing themselves.

The positive results and feedback from the initial workshop plus tutorials resulted in the Business Faculty making the workshops a compulsory part of the research support which is offered to EAL thesis and dissertation writers. The Faculty of Business has 
now offered the workshops together with one-to-one tutorials for language support six times. This has allowed the AL practitioners to reflect on and develop the workshops to fit student needs more tightly, and to adjust to special needs of each cohort.

Discussion and questions are encouraged throughout the workshops; a high level of engagement better informs the ALs of self-assessed student needs.

\section{School of Art and Design}

Working with exegesis and dissertation writers in The School of Art and Design started in 2006 and required a great deal of preparation to provide discipline-specific materials. The flexibility of the exegesis structure and the personalized approach required of the creative process led to considerable textual differences from one chapter to the next, as well as in the exegeses and dissertations of individual writers. Generic written parameters may therefore need to be fuzzy as compared to the more set parameters of dissertations and theses in Business. It has been another point of difference that in this School any student in the Masters program may participate in the workshops and receive one-to-one tutorials, and some of the most enthusiastic responses have come from native speakers. This may be because in this discipline creative performance is more highly rated than is written work, with writing seen as an adjunct to the creative arts, and thus fewer pre-dissertation written tasks have been required.

In order to provide a range of appropriate examples for the Art and Design students to demonstrate the use of discourse markers, lexical choice, and tense, the ALs not only used published theses, but also wrote a partial model exegesis on "Art and the Rubber Ducky”, which used generally accessible vocabulary (see Appendix for examples). Some of the published dissertations in this field were unsuitable for general pedagogical practice because the genre-specificity of lexical choices reflecting a genuine attempt at originality provided little commonality across individual works.

\section{Workshop Content}

The first of the workshops, as well as introducing the structure of the language support being provided, covers the overall structure of a thesis/exegesis and the need for the unifying use of metadiscourse and cohesive devices throughout. Further, a literature review from a thesis/exegesis written by a student from the appropriate field 
is analyzed and evaluated. In analyzing the literature review, its purpose is clarified, and appropriate discourse markers explicitly examined. The concept of an argument proceeding through logical stages to a conclusion is discussed. Short tasks of analysis and then synthesis using part of a published literature review are included, so the students have a "hands-on" experience. The theory of voice (Clerehan and Moodie (1997; Hyland, 2005) and the expression of this vital sign of the author's presence is clarified, with possible forms shown in examples. The workshop includes a close examination of the grading criteria set out in the postgraduate student handbooks, so students will be aware of the requirements for a high grade.

The second of the workshops includes explanation of the marking code used when an extract from the thesis, which is the basis for the individual tutorials, is first critiqued and returned to the writer. Uses of tense and punctuation to express meaning are explained, while choice of tense in citation is also discussed with suitable examples. A detailed presentation on cohesion and coherence is given, using short tasks and a range of examples for elaboration, again with discourse markers being highlighted. The style of formal register in thesis writing is also discussed, with contrasting examples of appropriate and poor usage. Examples of register are discussed for appropriateness, while problems of ambiguity are explored, and the rationale for the use of tentative language is examined.

The need for time management is highlighted, and a date set for the submission of the first 15-page section to be critiqued. This avoids the problem experienced the first time the course was run, when several students emailed a complete chapter with the request to check it before its submission the following day. The need to structure these submissions was recognized. It has also been necessary to explain that we are not a proof-reading service, and to refer students who want such a service to an appropriate contact provided by Student Services within the university, or to a professional proof-reader.

\section{Post-Workshop Tutorials}

After attending the workshops, dissertation/exegesis writers are entitled to two, and thesis writers to three, individual tutorials. The student submits to the designated AL 
(chosen at random) fifteen consecutive pages of work. The AL critiques the work, using the software Track Changes function and a marking code to designate the type of error. Additional comments are provided.

On the return of the critiqued writing, the student attempts to correct the identified problems, and then makes an appointment to meet with the AL. It is at this point of the process that the role of the student may change. There is a dialogue between the student and the AL in which the student is recognized as the discipline expert who needs to explain what may have been unclear in the writing. The process of explaining to a discipline outsider what is meant assists the student to clarify the expression of concepts The relationship between AL and student quickly becomes that of a partnership; oftentimes a good deal of humor and goodwill are involved. The concept of "text in process" (Lillis, 2003:396) best describes these tutorials. The AL treads a fine line between correction and suggestion, endeavoring to enable the student to find solutions that truly represent his/her intention. The AL does not usually see the final version of this writing, which goes instead to the supervisor. The intervention of the AL is seen by the students as a way of minimizing the power gap between themselves and their supervisors.

\section{Students' Needs}

Students at this level are usually aware of their weak areas in academic writing, although many have expressed dismay at the first piece of critiqued writing. 'I had thought my English was good' is a common response. This is generally because the students have limited their view to that of grammatical accuracy and basic individual chapter structure, and not the overarching structure of their work. A clear diagnosis of recurring problems facilitates their personal sense of learning the appropriate style for this level of academic writing. Experiential learning of academic writing in the time-honored master-apprenticeship manner is valuable as it can lead to the students' empowerment as successful academic writers. Turner (2004:95) refers to this as "a shift in conceptualisation from language as instrument to language as constitutive”. Students may also not be aware that what they have written is unclear to the reader. 


\section{Feedback}

The supervisors in the Faculty of Business are kept informed of the progress of each of their students and may be consulted for preferences relating to the author's voice and similar issues. While a small number of supervisors feel competent and have the time to deal with language problems themselves, the majority are glad to give over this task to the ALs. This is understandable given the finding from the research of Strauss and Walton (2005) that supervisors working with EAL students generally considered the supervisory workload doubled because of academic writing problems. Supervisors have found that all students supported by the workshops and tutorials are gaining on average an extra half grade on completion (e.g. a $\mathrm{B}+$ in place of a $\mathrm{B}$; in numerical terms an additional 5\%). Students have commented on the value of this support, and several have referred to the longer-term benefits in terms of promoting their academic careers. Others note their improved self-confidence in writing academic English. The ALs themselves notice considerable improvements between the first and last 15-page submissions; we appreciate, however, that in the space of six months to a year progress may be limited.

The ALs have learned the need to highlight a logical flow between sections and chapters to ensure that the overall structure of the thesis is apparent. Additionally in the workshops we now emphasize the importance of good time management to get most advantage from the tutorials. This has come about as a result of students not allowing sufficient time and coming to see us too late to truly benefit from our guidance. Particularly the international students appear to work within a very rigid timeframe. Dates are now set at the end of the workshops, in line with the date of submission.

\section{Reasons for Development of an Online Form}

One of our ongoing concerns has been that our support seems to be requested only after EAL students are found to be struggling with writing up their research. Too often it appears that students with obvious linguistic difficulties have been awarded reasonable marks in their postgraduate papers because discipline lecturers are more concerned with content than language. In their view the disciplinary content is the “real” academic work (Hamp-Lyons and Hyland, 2005:2). There is insufficient 
recognition of the fact that a student's ability to be a researcher "goes hand in hand with a sensitization to the possible uses of language for critically positioning themselves in relation to the field" (Clerehan and Moodie, 1997:74). As has been indicated, the students who attended both our workshops and tutorials made good progress, and their writing showed marked improvement. However, there were others who simply did not attend the tutorials, or requested them at a stage when it was far too late for us to be of real assistance. At the thesis writing stage, students have to come to grips with the complexities of research, and some have little time or energy to devote to the improvement of their language skills. It was clear that our assistance would better serve the students were it to be offered far earlier in their postgraduate careers, preferably in the first year of their studies.

The question was how best to offer this assistance. There were a number of considerations based on our experience of the workshops and tutorials based delivery of language support. First, it was essential to obtain faculty commitment, as students would only give our input serious attention if it was apparent that their faculty viewed it as important. Secondly, the faculty would need to make the workshop creditbearing. As Boud, Cohen, and Sampson (1999:1) point out, assessment is "the single most powerful influence on learning in formal courses”. We wanted to work alongside a discipline expert when we were developing our material. This is to ensure that the contextualization meets the requirements of the department and the needs of the students in that particular discipline.

A number of faculties indicated their interest in such a course, but another obstacle that needed to be overcome was the mode of delivery. One option which appeared to solve a number of our practical difficulties was online delivery. This mode of delivery offers a number of advantages, particularly in faculties where the majority of postgraduate students are part-time. It allows students maximum flexibility as to when and where they study. It also eliminates scheduling constraints. Another advantage for those faculties that cater for large numbers of international students is that these students could embark on their studies before they arrived in the country of study-in this case, New Zealand. The contextualization of the material will inevitably give students an insight into the postgraduate milieu at the university they will be attending. 


\section{Challenges Met for the Online Course Provision}

Difficulties are present in this approach for both lecturers and students. The students are drawn from a wide variety of linguistic and cultural groups. As McLoughlin (1999: 231) points out, there is a tension "between the need to ensure flexibility and access to learners of 'multiple cultures' while at the same time taking into account the need for localisation”. We have already highlighted the goodwill and sense of partnership that often result from our one-to-one encounters with the students. This is far more difficult to establish without face-to-face contact. Links between teacher and student arising from interpersonal contact, which Melrose and Bergeron (2007:2) define as "a non verbal manifestation of high affect", has been found to enhance student motivation. The benefits of affective learning are widely recognized. Despite this, we agree with Felix (2003:120) that "classroom teaching does not hold an automatic monopoly on best practice education” and believe that we can establish good online relationships with our students. Thus, current students are expected to attend two face-to-face workshops in addition to completing all online tasks. Although the workshops could easily be put online as self-access powerpoint presentations, we choose to use this format to provide the interpersonal contact we find valuable. The use of a virtual classroom is another alternative which we are investigating to provide the workshops, while using computers with cameras is an obvious solution for additional one-to-one support. As we found, the one-to-one interaction while critiquing students' work is the key to awakening their sense of academic worth so they can break free of the defined master-apprentice status inherent in the supervisory role. To establish best practice takes time, and any costing is bound to "overlook the many hours of unrecorded staff time involved in the process” (Felix, 2003:121).

These challenges are great, but we do not believe they are insurmountable: we have a number of advantages. Chanock (2007) makes the point that academic language and learning advisors often have the disadvantage of operating both structurally and metaphorically at the margins of academia. As ALs we teach in other relevant programs and supervise postgraduate students in our own discipline. In addition, our team is already involved in online delivery at postgraduate level. Perhaps most importantly, we believe that such a course helps to ensure that the unique contribution 
international students can make to the university community is not negated by “unhappy choice[s] of linguistic features” (Cadman, 1997:41), which may result in them inadequately expressing their concepts, and a corresponding downgrading of their achievements due to impaired language usage.

(4246 words) 


\section{References}

Allison, D., Cooley, L., Lewkowicz, J., and Nunan, D. (1998). Dissertation writing in action: The development of a dissertation writing support program for ESL graduate research students. English for Specific Purpose 11: 199--217.

Bitchener, J., and Basturkmen, H. (2006) Perceptions of the difficulties of postgraduate L2 thesis students writing the discussion section. Journal of English for Academic Purposes 5: 4--18.

Boud D., Cohen, R. and Sampson, J. (1999) Peer learning assessment Assessment and Evaluation in Higher Education 24(4): 413-- 426.

Cadman, K. (1997) Thesis writing for international students: A question of identity? English for Specific Purposes, 16: 3--14.

Cadman, K. (1997) The ‘songlines' of academic writing: Integrating the voices of international and NESB students into their texts. In R. Murray-Harvey and H. Silins (eds.) Learning and Teaching in Higher Education: Advancing International Perspectives HERDSA Conference, July 1997 Special Edition: 37--50. Adelaide: Flinders Press.

Canagarajah, S. (1996) Non-discursive requirements in academic publishing, material resources of periphery scholars, and the politics of knowledge production. Written Communication 13(4): 435--472.

Chanock, K. (2007). What academic language and learning advisors bring to the scholarship of teaching and learning: Problems and possibilities for dialogue with the disciplines. Higher Education Research and Development 26(3): 269-280 .

Clerehan, R., and Moodie, J. (1997) A systematic approach to the teaching of writing for supervisors of international students: Perspectives from genre theory. In R. M. Harvey and H. C. Silins (eds.) Learning and Teaching in Higher Education: Advancing International Perspectives. Proceedings of the HERDSA Conference, Special Edition: 73--91. Adelaide: HERDSA.

Cooley, L., and Lewkowicz, J. (1995) The writing needs of graduate students at the university of Hong Kong: A project report. Hong Kong papers in Linguistics and Language Teaching 18: 121--123.

Cooley, L., and Lewkowicz, J. (1997) Developing awareness of the rhetorical and linguistic conventions of writing a thesis in English: Addressing the needs of 
ESL/EFL postgraduate students. In A. Duszak (ed.) Culture and Styles of Academic Discourse. Berlin: Mouton de Gruyter.

Dong, Y. (1998) Non-native graduate students' thesis/dissertation writing in science: Self-reports by students and their advisors from two US institutions. English for Specific Purposes 17: 369--390.

Felix, U. (2003) Teaching languages online: Deconstructing the myths. Australian Journal of Educational Technology 19 (1): 118--138.

Green, B. (2005) Unfinished business: Subjectivity and supervision. Higher Education Research and Development 24 (2): 151--163.

Hamp-Lyons, L., and Hyland, K. (2005) Editorial for 4,1: Some further thoughts on EAP and JEAP. Journal of English for Academic Purposes 4: 1--4.

Hyland, K. (2002) Specificity revisited: How far should we go now? English for Specific Purposes 21: 385 --395.

Hyland, K. (2005) Representing readers in writing: Student and expert practices. Linguistics and Education 16: 363-377.

James, K. (1984) The writing of theses by speakers of English as a foreign language: A case study. In R. Williams, J. Swales, and J. Kirkman (eds.) Common ground: Shared interests in ESP and communication studies, ELT documents 117: 99--113. Oxford: Pergamon Press.

Jenkins, S., Jordan, M., and Weiland, P. (1993) The role of writing in graduate engineering education: A survey of faculty beliefs and practices. English for Specific Purposes 12: 51--67.

Lea, M. (2004) Academic literacies: A pedagogy for course design. Studies in Higher Education 29(6): 739--756.

Lillis, T. (2001) Student writing. Access, regulation, desire. London: Routledge.

Lillis, T. (2003) Student writing as ‘academic literacies’: Drawing on Bakhtin to move from critique to design. Language and Education, 17(3): 192--207.

Mackinnon, J. (2004) Academic Supervision: Seeking Metaphors and Models for Quality. Journal of Further and Higher Education 28(4): 395--405.

McLoughlin, C. (1999) Culturally responsive technology use: Developing an on-line community of learners. British Journal of Educational Technology 30(3): 231$-243$. 
Melrose, S. and Bergeron, K. (2007) Instructor immediacy strategies to work in online graduate study. Australasian Journal of Educational Technology 23(1): 132-148.

Nagata, Y. “Once I couldn’t even spell ‘PhD student’, but Now I are one!” Personal experiences of an NESB student. In Y. Ryan and O. Zuber-Skerritt (eds.) Supervising Postgraduates from Non-English speaking Backgrounds: 15--24. Buckingham: SRE and Open University Press.

Parry, S. (1998) Disciplinary discourse in doctoral education. Higher Education 36: 273--299.

Pearson Casanave, C., and Hubbard, P. (1992) The writing assignments and writing problems of doctoral students: Faculty perceptions, pedagogical issues, and needed research. English for Specific Purposes 11(1): 33--49.

Strauss, P., Walton, J., and Madsen, S. (2003) "I don't have time to be an English teacher." - Supervising the EAL thesis. Hong Kong Journal of Applied Linguistics 8: $1-16$.

Strauss, P. and Walton, J. (2005) Authorship, voice and the EAL thesis. In E. Manolo \& G. Wong-Toi (eds.) Communication Skills in University Education: The International Dimension 51--61. Auckland: Pearson Education, Prentice Hall. Thompson, P. (1999) Exploring the contexts of writing: Interviews with Ph D supervisors. In P. Thompson (ed.) Issues in EAP Writing Research and Instruction 37--54. Reading: Centre for Applied Language Studies, University of Reading.

Turner, J. (2004) Language as academic purpose. Journal of English for Academic Purposes 3(2): 95--109.

Vygotsky, L. (1978) Mind in Society: The Development of Higher Psychological Processes. Cambridge, MA: Harvard University Press. 


\section{Appendix: Examples used to illustrate features of a fictional exegesis, 'Rubber}

\section{Duckies in Art'.}

Introduction: History and Definitions and Use of In-text Referencing

The appearance of hollow rubber toys was first recorded in the 1700s. However the rubber duckie, as we know it today, appears to date from the twentieth century when indoor plumbing and baths became a standard feature in many houses. Its popularity was greatly boosted in 1970 by the song Rubber Duckie popularised by the television series Sesame Street (Meyer, 2006).

The toy has two variant spellings, "duckie” and "ducky," with the later (sic) being the most prevalent' (Meyer, 2006, p.14).

"The rubber duck can be referred to informally as a rubber duckie or a rubber ducky. Amongst collectors of rubber ducks, the spelling rubber duckie has achieved prominence, but both spellings are considered acceptable” (Retrieved 29 March 2007, from http://en.wikipedia.org/wiki/Rubber_duckies

\section{Strength of Claims}

Rubber duckies help children overcome bath time fears.

Rubber duckies may contribute to overcoming children's bath time fears.

Rubber duckies may play a small role in overcoming children's bath time fears.

Rubber duckies appear to play a significant role in overcoming children's bath time fears.

\section{Literature Review : Combining Ideas}

However the rubber duckie, as we know it today, appears to date from the twentieth century when indoor plumbing and baths became a standard feature in many houses (Meyer, 2006).

Glew (1994) mentions a poem apparently dating from the 1890s about a child and a rubber duck but has been unable to trace the poem.

\section{Literature Review: Tense}

This statement ....provides useful historical information about the popularity of a simple toy:

Primarily associated with children's bath time, rubber ducks have simultaneously emerged from the tub into a variety of new settings.

This article seeks to explore rubber ducks popularity by examining....

This article thus additionally argues that rubber ducks illuminate the interaction between children's culture and the larger adult popular culture.

Several misconceptions have arisen about rubber ducks...

By the 1940s, the Rempel company of Akron, Ohio sold several hollow walking rubber ducks.

What sets rubber ducks apart from other toys is their specific purpose.

\section{Use of Discourse Markers}

This research project has three aims. The first is to explore alternative methodological approaches that merge political philosophy and visual concepts focusing on the metaphor of the rubber duck. When these approaches have been analysed, it should be possible to arrive at a position relevant to contemporary art and international design practice. Finally a series of lithographs created to 
represent the global nature of ducks in human existence will exemplify this position.

The practical work represents a collection of different views based on the theme of rubber ducks. The work is sequenced (chronologically/ in order of importance/ using the effect of coloration with different media.) 